DOI 10.37882/2223-2982.2021.01.12

\title{
ПЕРСУАЗИВНЫЙ ПОТЕНЦИАЛ ФРАЗЕОЛОГИЗМОВ ДЛЯ ОЦЕНКИ СОБЫТИЙ И ХАРАКТЕРИСТИКИ ГЕРОЕВ (НА МАТЕРИАЛАХ АЗЕРБАЙДЖАНСКОГО ЯЗЫКА)
}

\section{PERSUASIVE POTENTIAL OF PHRASEOLOGISMS FOR THE EVALUATION OF THE EVENTS AND CHARACTERISTICS OF HEROES (ON THE MATERIALS OF AZERBAIJAN LANGUAGE)}

\section{Ismayilova M. Driga}

Summary: The article is devoted to the phraseological units of the «Negative character traits» microfield (based on the materials of the Azerbaijani language). The article contains phraseological units that reflect such negative qualities as rancor, intemperance, disrespect, sycophancy, irascibility, ignorance, illiteracy, distrust, indifference, cunning insidiousness, avarice, dishonesty, servility, hypocrisy, arrogance, pitiful person, shamelessness. In the article, the authors adduce phraseological units used in various situations.

Keywords: phraseological units, incontinence, disrespect, rancor, mistrust, stinginess, dishonesty, servility, hypocrisy, arrogance, cunning sycophancy, irascibility, ignorance.
Исмайлова Лейлаханум Гусейн кызы
К.филол.н., доцент, Военный университет МО РФ (Москва)
Leylaxanum@mail.ru
Дрига Марина Владимировна
Стариий преподаватель, Военный университет МО РФ

(Москва)

Dr_mari@mail.ru

Аннотация: Статья посвящена фразеологизмам микрополя «Негативные черты характера» (на материале азербайджанского языка). В статье собраны фразеологические единицы, отражающие такие негативные качества, как злопамятность, несдержанность, неуважение, подхалимство, вспыльчивость, невежественность,

неграмотность, недоверие, равнодушие, хитрость коварство, скупость, нечестность, угодничество, лицемерие, надменность, жалкий человек, бесстыдство. В статье авторы приводят ФЕ, используемые в различных ситуациях.

Ключевые слова: фразеологические единицы, несдержанность, неуважение, злопамятность, недоверие, скупость, нечестность, угодничество, лицемерие, надменность, хитрость подхалимство, вспыльчивость, невежественность, неграмотность, равнодушие, коварство.
Я зык как знаковая система не просто обозначает мир, но и интерпретирует все то, что так или иначе зафиксировано и осмыслено в сознании человека, в том числе и его эмоциональное состояние.

Фразеологические единицы играют огромную роль в реализации регулятивной функции речи, поскольку именно они обладают способностью в наиболее яркой, образной и экспрессивной форме выражать чувства от радости и восторга до печали и скорби, тем самым оказывая наиболее мощное персуазивное воздействие.

Фразеологические единицы создавались в языке годами, они связаны с культурой народа, его историей, географией. Каждая фразеологическая единица имеет свою историю и национальный колорит. Фразеологизмы используются в речи как в ходе повседневного общения, так и при соблюдении традиций и обрядов.

Фразеологизмы микрополя
«Негативные черты характера»
Коварство

О коварном человеке в языке существует выражение
«Birisinə quyu qazmaq» [букв.:рыть могилу кому - то] «рыть Әругому яму». В просторечии наиболее часто используется ФЕ «Qәbir qazmaq» [букв. рыть могилу] «рыть могилу». Когда поступают с кем-то жестоко, используют выражение «Işini burmaq» [букв. закрутить его дело] - «подложить свинью»; "Aşına zəhər qatmaq» [букв. подмешать в плов яд] - «делать жизнь невыносимой»; Ayağının altını qazmaq [букв. копать под ногами] «устроить ловушку».

\section{Ситуация 1:}

«-Üzümə gülür, mənimlə duz çörək kəsir, arxada ayağının altını qazır, kələk gəlir.

- Kimin haqqında danışırsan?

- Iradə haqqında. Evimə gəlir gedir, işimi burur.

- Он смеется мне в лицо, делит со мной хлеб-соль, а за спиной роет мне яму, хитрит.

- Про кого ты говоришь?

- Про Ираду. Приходит ко мне домой, а сам под меня кonaem.»

\section{З^опамятность}

Про человека, который очень долго помнит зло, 
никогда не простит обиду и при первой возможности будет мстить, говорят «Dәvә kini» [букв. злоба верблюда] - «злопамятный, как верблюд». В азербайджанской литературе у многих писателей в произведениях встречаем такое выражение как «dəvə kimi kinli», «dəvə kini» - злопамятный, как верблюд. Говорят, что верблюды не просто помнят зло, причиненное им, но не успокоятся, пока не отомстят. Они долго молча терпят, не показывают обиды, но когда настанет благоприятный момент, когда он останется один на один с обидчиком, тут от него можно ожидать чего угодно, он может растоптать, даже убить человека. Таким же мстительным и злопамятным может быть и человек. Вот и про таких и говорят, что он «злопамятен, как верблюд».

\section{Нечестность}

Про человека, который обманным путем берет у людей деньги и не возвращает, говорят: «Baş qırxan»; «Baş qırxmaq" [букв. брить голову] - ««проходимец»; "Qоçи Nəcəfqulunun keçisi». Когда говорят о нечестном человеке, вспоминают ФЕ «Isfahan lotusu» / [букв.: исфаганский пройдоха] - «мошенник, шулер». Почему исфаганский? Происхождение этой ФЕ связано с историей правления шах Аббаса в Иране. До правления шах Аббаса город Исфаган был небольшим городом. Но Шах Аббас переносит столицу из Тебриза в Исфаган. Со всех районов в столицу переезжали люди. Были среди них и мошенники, и шулеры. Им было легко в многонаселенном городе делать свои грязные дела. Так выражение «Isfahan lotusu» исфаганский пройдоха и вошло в азербайджанский язык.

В произведении Джалила Мамедгулузаде «Ölülər» один из главных героев, Искендер, говорит своему отцу:

«- Вы все верите шейху, что он оживит ваших умерших, готовы отдать ему за это все свое состояние, даже и не приходит вам в голову, что он «исфаганский шулер».

\section{Угодничество, подхалимство}

Про человека, который ради своих корыстных целей готов угодничать и подхалимничать, говорят: "Yala hürmək» [букв. лаять на собачью еду] «nодхалимничать», «лизать пятки», «плясать под чьюлибо дудку», т.е. угодничать, как собака, которая ради еды готова перед любым вилять хвостом. Ситуация 1:

«-Ona sən fikir vermə, o yala hürəndir, kim ona nə versə, onun tərəfini saxlayacaq».

«- Ты на него не обращай внимания, он подхалим, кто что ему даст, того он и будет поддерживать».

Quyruq bulayan / [букв.: тот, кто хвостом виляет] мелкая сошка

Синонимы: «Tәrifini göуә qaldırmaq» / [букв.: поднять хвалу до небес] / рассыпаться в похвалах

«Oriştə doğramaq» / [букв.: резать лапшу] // лапшу на уши вешать, льстить,

\section{Неслержанность, вспыльчивость}

Про человека, не умеющего владеть собой, теряющего самообладание, говорят: «Özünü saxlaya bilməmək» [букв. он не может себя сдерживать] - «не умеет вести себя». Ситуация:

«-Məniyenə məktəbəçağırıblar.Yenə deyəcəklər:oğlunuz özünü saxlaya bilmir, yerdən qışqırır.

- Меня опять вызывают в школу. Опять будут говорить: ваш сын не умеет себя вести.»

\section{Невежественность, неграмотность}

Про человека, который не умеет ни читать, ни писать, могут сказать: «iki eşşəyin arpasını bölə bilmir» [букв. не умеет делить ячмень между двумя ослами] - «ни в зуб ногой». Ситуация:

«-Elə savadsızdır ki, iki eşşəyin arpasını bölə bilmir.

- Такой неуч, что ни бе, ни ме не знает.»

\section{Неуважение}

Про плохого человека, недостойного уважения, говорят «Adı it dəftərində yoxdur» [букв.: его имени нет в собачьей тетради]. Во времена монгольского ига, враги грабили, сжигали все на своем пути, забирали женщин и мальчиков. Азербайджанцы решили платить завоевателям любую дань, лишь бы защитить свои семьи. Тогда монголы начали проводить перепись населения, завели тетради, куда записывали имена трудоспособных мужчин. Женщин, стариков и детей не записывали. Те, чье имя попадало в список, вынуждены были платить налоги, так что попасть в эти тетради было большим горем. Со временем в народе и в литературе появилось выражение собачья тетрадь. И если о ком-то скажут, что его имени нет даже в собачьей тетради., значит, речь идет о недостойном, дурном человеке [Адилов, 1982: 140].

В просторечии могут использовать следующие синонимические ФЕ: «Üz çevirmək» [букв. личо повернуть] «воротить рожу» (грубое выражаение); «Üz döndərmək» [букв. отворачивать лицо] - «поворачиваться спиной»; "Adam yerinə qоутатаq" [букв. не ставить на место человека] - «ни во что не ставить», «не считать за человека»; Sәni it yerinə də qоymuram [букв. пебя не ставлю даже на место собаки] - «обращаться, как с собакой». Ситуация: отрывок из произведения Д.Мамедгулузаде:

«- Mәn ölüm, Hәsәnəli, yekə-yekə danışma! Hәуә sәn kişi idin, binəva Suleyman bəуə vaxtında patron yetirə idin.

- Ради Бога, Гасанали, не хвастайся! Ты был мужчиной, вовремя доставил патроны бедному господину Сулейману».

\section{Недоверие}

Если человеку не доверяют, используют выражение «ipinin üstünə odun yığmaq olmaz» [букв. нельзя поло- 
жить дрова на его веревку], что означает «ненадежный, хитрый человек, на которого нельзя положиться». В древние времена считалось, что люди связаны веревкой, т.е. узами дружбы, братства. О человеке, на которого нельзя положиться, в народе говорили, что он «порвал веревку, которой был связан». Вообще, слово веревка - понятие, означающее богатство, жизнь. Поэтому про состарившего человека говорят, что его веревка стала очень тонкой и рвется. Есть такое выражение: разорвал отношения, т.е. разорвал нити, связывающие людей. Отсюда и ФЕ «Ipinin üstünə odun yığmaq olmaz», т.е. на его веревку нельзя собрать дрова, потому что веревка или тонкая, что говорит о том, что отношения натянутые, или вовсе уже не существует. Или человек настолько хитер, что на его веревку нельзя собрать дрова, потому что в любой момент она может оборваться». Ситуация: в произведении «Ашуг Алескер» говорится о том, что у Алескера был друг Гара. Как-то Гара пригласил ашуга Алескера на свадьбу. Алескеру не хотелось идти на свадьбу. Гара очень сильно разозлился. И в ярости Гара едет к Алескеру, протягивает ему один конец веревки из козьей шерсти и говорит:

- Держи!

И когда ашуг Алескер схватил за конец веревки, Гара достал из кармана нож и сказал:

- Если ты со мной не пойдешь на свадьбу, то я сейчас разрежу эту веревку, и мы больше не будем друзьями.

Ашугу Алескеру ничего не оставалось, как пойти с ним на свадьбу, потому что он ченил их дружбу» [Адилов, 1988: 140]

ФЕ «bel bağlamamaq» [букв. пояс не завязывать] «не надеяться ни на кого». Ситуация: отрывок из произведения Абдулрагим бека Хаквердиева:

«- Naçalniklərə, pristavlara, yasavullara bel bağlamaq olmaz.

- Начальникам, приставам, есаулам нельзя доверять».

\section{Равнолушие}

Когда хотят охарактеризовать равнодушного человека, который ни о ком не переживает, никому не сочувствует, который не может или не хочет чувствовать чужое страдание, чужую боль. используют выражения: «Ürәуі pas tutub» [букв. сердие покрылось ржавчиной] «сердие обросло мхом». Могут использоваться и более образные, стилистически окрашенные выражения, такие как: «Araz aşığından Kür topuğundan» [букв.: Араз по щиколотку, Кура по лодыжку] - «море по колено». Cитуация: «-Sәmədin də dədəsi kimi, Araz aşığından Kür topuğundan». (Самеду, как и его отцу, море по колено.)

\section{Хитрость}

Когда азербайджанцы хотят сказать о таких качествах человека, как хитрость, ловкость, лукавство, о человеке, который скрывает свои истинные намерения, и который для достижения своих целей готов идти непрямым, а обманным путем, говорят: «Şeytana papaq tikmək» [букв. шить шапку черту]. Также могут использоваться и такие синонимы: «Tülkünün quyruğu» [букв.: лисий хвост] - «хитрый лис»; "Qоyun dərisinə girmiş canavar» [букв. волк в овечьей шкуре]; "Az aşın duzu deyil» - звучит как незлобное порицание «еще тот хитрец!»; «Tülkü kimi bicdir» [букв. хитрый, как лиса]; Allahın bici [букв. божий хитрец] - «себе на уме»; Yerin altını da bilir, üstünü də [букв. знает, что происходит под землей, и над землей] «пальца в рот не клади».

Ситуачия: отрывок из произведения М.Ф. Ахундова.

«- Amma Ağa Salmana mənim təlimim lazım deyil. O özü şeytana papış tikər. - Но господину Салману мои учения не нужны. Он сам самого черта обучет».

Ситуация: отрывок из произведения Е. Султанова.

- Sənin bicliyini kim bilmir, sən az qalırsan ki, şeytana papış tikəsən, sən mətləbi başa düşmürsən? - Kmо не знаem о твоей хитрости, ты чуть ли на ходу подметки рвешь, ты не понимаешь суть? (Тагиев, 2006: 185):

Ситуачия: отрывок из произведения С. А. Ширвани. «Dağılıb çöllərə açdı hərə bir növ kələk.

Qırxdıxalqın başını hər biri misli-dəllək.

Разбревшись кто куда, придумал каждый во что горазд,

Обрили народ по - своему, обманув его каждый раз.»

\section{^ичемерие}

Про притворщика, который скрывает свое настоящее лицо, скажут: «Qoyun dərisinə girmiş qurd» [букв.: волк в овечьей шкуре]. Так говорят о двуличных, подлых людях, которые скрывают свои истинные помыслы под маской порядочности. Эта ФЕ происходит из Торы и получила широкое распространение с давних времен как на Западе, так и на Востоке. В произведении А. Шаига «Мои воспоминания» говорится: «После того, как узнали про грязные дела моллы Гасана, алтыбармаг Сеид (у Сеида было 6 пальцев - алтыбармаг и его так и звали алтыбармаг (еид) рассказал всем про него и опозорил, сказав: «Эй, мусульмане! Это голодный волк в овечьей шкуре, на какие деньги он купил этот огромный дворец на берегу Куры?».

В просторечии могут использоваться такие синонимы, как: «Özünü tülkülüyə qоутаq» [букв. лисой прикидываться] - «надевает маску»; Оуип с̧ıхагтаq [букв.: играть игру] - «ломать комедию» (Тагиев, 2006: 164):

«- Hər şeyi bilir, amma danışmaq istəmir, özünü tülkülüyə qoyur.

- Все знает, но говорить не хочет, надевает маску.» 


\section{Намменность}

Про самодовольно-высокомерного, кичливого человека говорят как бы от его имени: «Burda mənəm, Bağdadda kor Xәlifə» [букв.: здесь я, а в Багдаде слепой Халиф]. Происхождение этой ФЕ связано с историей правителей. В начале $\mathrm{X}$ века в Багдадском халифате шла яростная борьба за престол. И в конце концов, некоторых правителей лишали законных прав, а некоторым даже выкалывали глаза. Самым первым халифом, которому выкололи глаза, был Аль-Кахир. Он 17 лет бродил по стране, как нищий. Некоторые халифы через многие годы смогли вновь подняться на престол, хоть и слепыми. Отсюда и пошло выражение «Burda mənәm, Bağdadda kor Xəlifə» / здесь я самый главный, а в Багдаде слепой Халиф.

\section{Бесстылство}

Выражение «Üzündə abır-haya olmamaq» [букв.: на лице нет стьда] употребляют, когда говорят о бесстыжем человеке. Иногда говорят: «üzündə su yoxdur» [букв.: на его личе нет воды]: «- Bu kişinin heç abır-hayası уохdur». (Уэтого мужчины ни стыда, ни совести.)

В азербайджанском языке есть ФЕ «At balaxanım» [букв.: лошадь Балаханум] - «бой баба». Балаханум женское имя. Когда речь идет о грубой, скандальной и бесстыжей женщине, употребляют это выражение. Женщин с древних времен в Азербайджане ассоциировали с красивым благородным оленем - маралом. Исторически так сложилось, что с конца XIX века в азербайджанском языке появилось слово адмирал. Но в народе это слово было непонятно, и поэтому превратилось в слово "atmaralı», а чуть позже слово at был соединен к слову Balaxatın. Слово адмирал, превращенное в atmaralı, могло относиться и к мужчинам, но выражение «At balaxanum» применяется только по отношению к женщинам». Кроме этой ФЕ, есть еще и такая: «Yeyib halvanı, minib eşşəуі» [букв. съел халву, сел на ишака]. Употребляют эту ФЕ, когда говорят про невоспитанного и бесстыжего человека. Происхождение этого выражения связано с очень древним обычаем. Во многих восточных странах практиковался такой вид наказания, когда провинившегося целую неделю кормили самыми вкусными блюдами, сладостями, халвой, а потом его сажали на осла задом наперед. Так его везли напоказ всему селу или городу, на потеху народу. Осужденного оскорбляли, плевали ему в лицо, и только потом его казнили. С тех пор когда речь идет об очень непорядочном человеке употребляют эту ФЕ».

\section{Скупость}

Когда говорят о чрезмерно жадном, ненасытном и скупом человеке, употребляют ФЕ «Ac qurd» [букв. голодный волк]. (Оруджев, 1976, - С 59). О скупом человеке могут сказать и так: «Barmağından su dammaz» [букв. $c$ пальца его вода не капнет] - «зимой снега не выпросишь». ФЕ «Әli әsmək» [букв.: руки трясутся] используют, когда говорят об очень жадном человеке, скупом, расчетливом. (Оруджев, 1976: 137).

Могут использоваться в просторечии такие синонимы: «Ölü eşşək axtarır nalını çıxartsın» [букв. uщет cдохшего ишака, чтобы снять его подкову]; "Gözӥ doymur» [букв. глаза не насытятся] (Оруджев, 1976: 175); «Qışda gar almaq olmaz» [букв. зимой нельзя выпросить снега]; «Daş qәhvədanı" [букв.: каменная кофемолка] - «дрожать над каждой копейкой»:

«- Ay sənin qadanalım, xalan daş qəhvədanıdır, qışda gar almaq olmur.(Родная, у твоей тети зимой снега не выпросишь, дрожит над каждой копейкой).

\section{ХКалкий человек}

Когда говорят о несчастном, жалком человеке, употребляют ФЕ «Dəvəsi öımüş әrəb» [букв. араб, у которого подох верблюд] - «бедняга». Арабы, которые ведут кочевой образ жизни, считают, что верблюды самые умные, терпеливые и выносливые животные. Вместе с верблюдом араб мог передвигаться по знойной пустыне. И если верблюд в пути подыхал, то это было настоящей трагедией для араба. Поэтому, когда хотят сказать о жалком человеке, его сравнивают с арабом, у которого сдох верблюд. Cuтуация 1:

- Dəvəsi öımüş ərəb kimi niyə orda dayandın, içəri keç, süfrəуә уaxın otur. (Почему, бедняга, стоишь там, проходи, присаживайся к столу.)

Благодаря своей эмоциональной и оценочной насыщенности фразеологические единицы активно используются говорящим для регулятивной персуазии в коммуникативном дискурсе. Эмотивные фразеологические единицы составляют значимый корпус эмоционально экспрессивных и стилистически окрашенных средств языка и берут на себя основную роль в регуляции коммуникативного дискурса.

\section{ЛИТЕРАТУРА}

1. Мамедкулизаде Дж. Избранные произведения. - Баку, 1966. - Т. 2.452 с.

2. Адилов М., 1982, -242 с. 
3. Ахвердиев А. Избранные произведения. 2005, - 408 с.

4. Тагиев М.Т., Русско-азербайджанский фразеологический словарь. 2006, - 185 с.

5. Оруджев А.А., Азербайджанско-русский словарь. 1976, - 248 с.).

○ Исмайлова Лейлаханум Гусейн кызы (Leylaxanum@mail.ru), Дрига Марина Владимировна (Dr_mari@mail.ru).

Журнал «Современная наука: актуальные проблемы теории и практики»

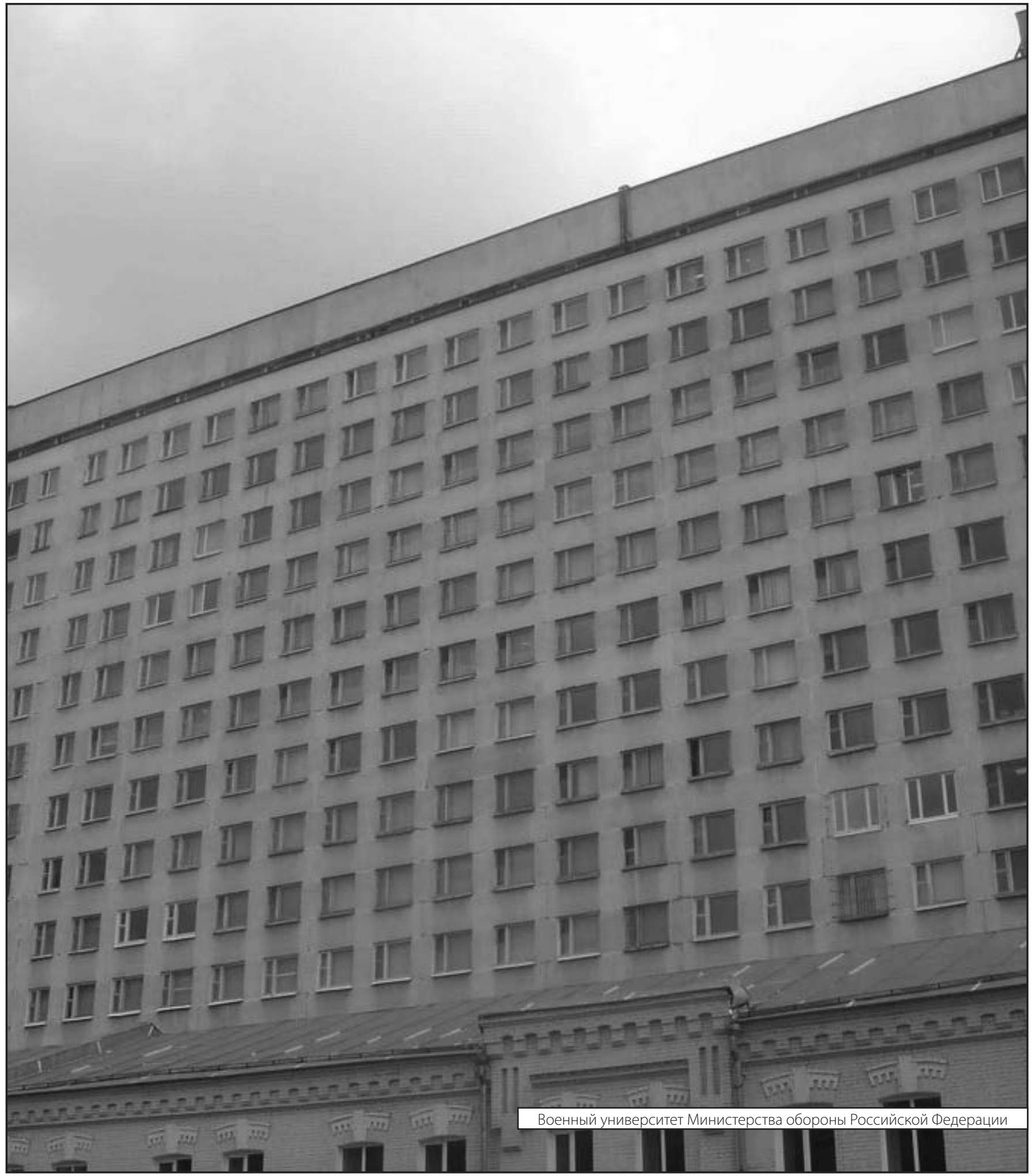

